\title{
Another look at color primitivism
}

\author{
Pendaran Roberts ${ }^{1,2}$
}

Received: 16 August 2017 / Accepted: 17 May 2018 / Published online: 31 May 2018

(C) The Author(s) 2018

\begin{abstract}
This article is on a precise kind of color primitivism, 'ostensivism.' This is the view that it is in the nature of the colors that they are phenomenal, non-reductive, structural, categorical properties. First, I differentiate ostensivism from other precise forms of primitivism. Next, I examine the core belief 'Revelation,' and propose a revised version, which, unlike standard statements, is compatible with a yet unstated but plausible core belief: roughly, that there are interesting things to be discovered about the nature of the colors. Finally, I show that ostensivism is the only view on color that can accommodate both proposed core beliefs.
\end{abstract}

Keywords Color · Phenomenal · Core beliefs · Color primitivism · Revelation · Realism · Relationalism · Objectivism · Anti-relationalism

\section{Introduction}

Views on what the colors are can be divided into two categories: reductive and nonreductive. There are many precise reductive views. Appearance dispositionalism is a reductive view to the effect that the colors are dispositions to appear certain ways if certain generally specified conditions are met; for example, red is the disposition to appear red to a normal subject if viewed in normal circumstances (McGinn 1983; Johnston 1992; Levin 2000). Another reductive view is 'micro-structuralism:' the colors are micro-structural properties (Smart 1963; Armstrong 1968), for example, having a certain electronic configuration. A more contemporary challenger is 'reflectance

\footnotetext{
$凶$ Pendaran Roberts

Pendaran@mac.com

1 Department of Philosophy, University of Warwick, Coventry, UK

2 University of Johannesburg, Johannesburg, South Africa
} 
dispositionalism:' the colors are dispositions to reflect certain proportions of incident light at each wavelength of the visible spectrum (Tye 2000; Byrne and Hilbert 2003, 2004). Finally, there is Cohen's relational view (2004, 2009), which, like the above views, is reductive (see for example, Cohen 2009, p. 10, footnote 16). His relational view is that the colors are reductively constituted by relations to subjects.

Compared to reductive views, there is a paucity of precise, non-reductive, also called 'primitivist,' views. Many statements of primitivism are vague or unclear (Campbell 1993; Yablo 1995; McGinn 1996; Chalmers 2006). I develop a precise version of primitivism, 'ostensivism,' designed to better accommodate certain core beliefs. First, I explain ostensivism in detail (Sect. 2), clarifying how it is different from other precise primitivist views. I then examine the well-known core belief, 'Revelation' (Sect. 3). I propose a revised version, 'Phenomenal Revelation,' which, unlike standard statements, is compatible with a yet unstated but plausible core belief, 'Depth.' Depth is (roughly) that there are interesting things to be discovered about the nature of the colors. Finally, I show that ostensivism is the only view on color (including reductive views and other precise primitivist views) that can accommodate both Phenomenal Revelation and Depth (Sect. 4) and so is superior in this respect. This argument is not meant to be conclusive. I have a modest aim: to propose a precise variant of primitivism and show why it has an advantage over other views on color.

\section{What is color ostensivism?}

Primitivism is the view that the colors are non-reductive properties in whatever cogent way or ways shapes are. As will become clear, the view I propose, ostensivism, is a precise kind of primitivism, but one that is incompatible with other precise kinds of primitivism. Many formulations of primitivism lack the precision to say for sure whether ostensivism is incompatible with them, but there are two recent formulations of primitivism that are, in my opinion, precise enough. The first such precise kind of primitivism is that all truths about the nature of the colors are 'chromatic truths' (Byrne and Hilbert 2007): if a proposition $p$ is about the nature of the colors, then $p$ is expressible only using a purely chromatic sentence (see Sect. 2.6 for more details). The second precise kind of primitivism is a view analogous to the view that 'arithmetical truths do not need to be explained in terms of anything other than the most basic truths about numbers: truths we learn when we learn to count out loud and when we learn to count out how many objects are in a collection' (Gert 2008, p. 130). The view goes like this: all fundamental truths about the colors are the kinds of simple (or easy) things ordinary people know. ${ }^{1}$ An implication of this is that nothing informative can be said about what the colors are (as the footnote points out, Gert wants this implication). I categorize these two recently articulated primitivist views

\footnotetext{
1 Some disagree about the quietist nature of the view Gert (2008) proposes. Thus, I will here provide some support for my formulation of his view. Gert holds that his view is that there are no informative or non-trivial truths about what the colors are (personal correspondence). My formulation of his view captures this. He also wants the analogy he makes with arithmetical truths to be rather tight (personal correspondence). My formulation draws a tight analogy between the stated view on arithmetical truths and his view on color.
} 
as, 'Primitivism' ('Primitivism' italicized). Primitivism is a kind of color quietism. This will become clearer later on.

\subsection{Ostensivism defined}

Ostensivism holds that the colors are chromatic phenomenal properties. I mean something very precise by this: that the intrinsic natures of the colors are those phenomenal properties that ostensively define the phenomenal characters of experiences as of objects having colors. (The intrinsic nature of something can be understood as being what that thing is most fundamentally. It is what that thing really and ultimately is, in reality.) $)^{2}$ Thus, ostensivism holds that the intrinsic natures of the colors are the phenomenal colors or the colors as we see them. These are the properties by which we define the phenomenal characters of experiences. Consequently, the intrinsic natures of the colors are not hidden from our immediate experience like those of the physical sciences: the redness phenomenally presented in experience, appearing to cover the surface of the tomato, that is the intrinsic nature of red. In other words, according to ostensivism, the intrinsic natures of the colors are (completely) given by their phenomenal characterizations: that they are like that and that... Consider the way a tomato looks when it looks red; the intrinsic nature of red is given by that way of looking. Non-ostensivist views deny this. They hold that the intrinsic natures of the colors are not given by their phenomenal characterizations. For example, physicalist views (as normally understood) hold that the intrinsic natures of the colors are given by physical descriptions.

Ostensivism implies some very interesting things about the nature of the colors. (Things that are merely in the nature of the colors as opposed to being their intrinsic natures are still fundamental to the colors but less so; they are things that are determined by the intrinsic natures of the colors.) The intrinsic natures of dispositions are not (completely) given by phenomenal characterizations; they require descriptions, for example, 'the disposition to appear red to normal observers in normal conditions.' Dispositions connect objects with counterfactuals in a special way that non-dispositional properties (also called 'categorical properties') do not. Thus, ostensivism implies that it is in the nature of the colors that they are categorical properties and so do not have the special connection with counterfactuals that dispositions do. More specifically, ostensivism implies that it is in the nature of the colors that they are structural, categorical properties. A structural property, as I define it, is a property that is defined over multiple dimensions. The colors, as phenomenal properties, are defined over multiple dimensions: hue, saturation, and lightness. ${ }^{3}$

\footnotetext{
2 The use of 'intrinsic' in 'intrinsic nature' should not be taken to imply that a property which is not the intrinsic nature of something must be extrinsic to that thing. The word 'intrinsic' in 'intrinsic nature' is different from the sense of the word used in the intrinsic/extrinsic property of objects distinction, at least the way I am using it. The intrinsic nature of a property might in fact be such that the property is an extrinsic property of objects.

3 The Munsell color system uses chroma instead of saturation for surface colors. Arguably there are fundamentally different kinds of color: surface colors, film colors, aperture colors. These are said to differ in their exact dimensions (Maund 2012). It may be the case that the colors or some colors have additional
} 
Shapes are structural, categorical properties too. The assumed view of shapes is that they are categorical (non-dispositional) and, like colors, vary over certain dimensions: number of sides, length of sides, and internal angles. There is another similarity between shapes and colors if ostensivism is true, a similarity that is important to ostensivism being a primitivist view on color. The assumed view of shape is that shapes are non-reductive properties in the sense that they are not identical with any properties that are not as we see them (shape properties themselves are as we see them, even if external world objects do not always have the properties we see them as having). Ostensivism is non-reductive in the same way. ${ }^{4}$ The view holds that the colors are not any properties that are not as we see them. Ostensivism holds that the intrinsic natures of the colors are the phenomenal colors or the colors as we see them. Thus, in sum, color ostensivism tells us that the nature of the colors is that they are chromatic phenomenal properties that are similar in kind to shape properties: both colors and shapes are non-reducible, structural, categorical properties.

\subsection{Some criticisms of the notion 'phenomenal property'}

1. Phenomenal concepts such as those employed above have been shown defective by Wittgenstein's private language argument (henceforth, 'PLA') (Wittgenstein 1953, sections 243-293). First, it is important to note that it is not set in stone that phenomenal concepts are indeed inconsistent with the PLA (Papineau 2011). Putting this aside, phenomenal concepts are not merely relevant to my theory but to all sorts of arguments in the philosophy of mind, including Jackson's famous knowledge argument (1982). So, I will not address this Wittgensteinian worry with phenomenal concepts in any depth. A discussion of the PLA and a survey of possible responses to the PLA is really beyond the scope of this work. Suffice to say, I agree with Papineau (2011) that Wittgenstein's PLA, if incompatible, sets the bar for meaning too high. If a reader desires to learn more, they could start with the cited paper.

2. Phenomenal properties are unexplainably rich. This concern involves most directly my claim that 'the colors, as phenomenal properties, are defined over multiple dimensions: hue, saturation, and lightness.' In reply, I believe what the ostensivist should say is that all explanations must come to an end sooner or later, and when it comes to what explains the richness of phenomenal properties, the end comes sooner rather than later. The ostensivist cannot accept a reductive account of the structural properties of the colors. The structural properties of the colors must be determined by what the colors are most fundamentally (their intrinsic natures), and for the osten-

Footnote 3 continued

or different dimensions. Perhaps there are more dimensions than human eyes can see (Thompson 1995, pp. 141-160; Allen 2009). These are complications that are not important to the goals of the present paper. All I need my reader to accept is that the colors are defined over multiple dimensions (not necessarily the same ones).

4 This analogy should not be confused to imply that shape properties are phenomenal properties (or to imply that there are physical and phenomenal shapes). If it will aid understanding, one might think in Lockean terms: the assumed view of shape is that our perceptions of shapes match the nature of shapes. Put this way, the analogy is that with ostensivism, analogous to the assumed view on shapes, our perceptions match reality. 
sivist, what they are most fundamentally is given by pointing. So, the ostensivist's only explanation for why the colors have the structure they do is to say, 'what explains their structure is that they are like this, that, and that' (pointing). In other words, what fundamentally explains the structure of the colors is how they look, according to ostensivism. This is an explanation, but it is a phenomenal, non-reductive explanation.

3. Phenomenal properties function as explanantia by having built in, merely by stipulation, all the features of the explanandum. This is a related concern to the first. However, instead of claiming that the richness of phenomenal properties is unexplainable, this criticism claims that phenomenal properties can explain the structure of the colors (and perhaps the other properties in their nature too) only circularly. Here we must tread carefully. A circular explanation merely builds the answer into the explanation in such a way that it fails to provide any new information; for example, 'the colors have a structure, because they have a structure.' Perhaps a philosopher might read this answer as asserting a kind of primitivism, but literally, as written, it does not provide anything new; it is circular. Ostensivism is primitivist, not circular. Suppose someone were to ask, 'why is green more similar to yellow than to red?' The ostensivist's reply is to assert that the answer most fundamentally involves the phenomenal natures (pointing) of the colors in question. This is not circular, or at least it is not circular in the sense of providing no new information.

4. Descriptive truths about the colors, e.g. that they have structure, cannot be determined by non-descriptive, phenomenal facts, i.e. how they look. In reply, I simply reject this claim. I assert that they can. One need only remove one's reductivist goggles to see that this is true. Some descriptions are made true by spatial facts, some are made true by temporal facts, some are made true by mathematical facts, and some are made true by phenomenal facts. According to ostensivism, what the colors are most fundamentally are phenomenal properties. Therefore, according to ostensivism, all true descriptions about the nature of the colors are determined by phenomenal facts. This kind of view will not be popular with reductivists. However, it is not an odd or weird or mysterious idea that what makes it true that, for example, 'green is more similar to yellow than to red' is how these colors look; it is a perfectly intuitive and ordinary thought.

\subsection{Ostensivism and irrealism}

My view, ostensivism, is compatible with realism (the view that external objects are actually colored) and with different kinds of irrealism. ${ }^{5}$ It looks in perception as if external objects have phenomenal color properties (look at something), suggesting

\footnotetext{
5 If ostensivism is compatible with irrealism, does this mean that the view implies that the colors are only contingently related to underlying micro-physical properties? The sense in which ostensivism is compatible with irrealism is logical. So, this leaves room for saying that metaphysically, irrealism is impossible. The ostensivist may wish to adopt this metaphysical stance to avoid sceptical worries. Imagine a twin-earth exactly like this one except that nothing is colored. Twin-earth would look colored but not be. I think there is no need to reject what I consider to be the intuitive position that colors are only contingently related to underlying micro-physical properties, because really the sceptical concern in question is just an instance of scepticism about the external world (for some related discussion regarding quiddistic knowledge, see Schaffer 2005).
} 
that realism is the default position based on how things look. This said, nothing in the formulation of ostensivism logically requires the phenomenal properties identified with the colors to be had by external objects rather than internal ones (e.g. sense data, see Jackson 1977) or by any objects whatsoever (Chalmers 2006). Ostensivism does not imply that how objects look with respect to colors is how they are; it only implies that the colors, as properties, are as they look. If the phenomenal properties are had by internal objects, we can be understood as pointing at them; if they are not had by any objects, we can be understood as pointing at merely possible color properties (not actually instantiated). What is necessary for this to work is that for what we are pointing at not to be determined purely internally. We can think we are pointing at something actually in front of us but really be pointing at something in our minds or in purely logical space. Given the popularity of externalist views of content (Putnam 1975), this externalist perspective on ostensive definitions cannot be assumed false. ${ }^{6}$

Whether realism or some variant of irrealism is correct is not something I will discuss. The purpose of this article is to propose a precise version of primitivism and show why it has an advantage over other views on color; it is not to argue that realism or irrealism is true. If ostensivism ultimately meant that some form of irrealism were true, this would be a strike against the view, but it is hard to imagine why ostensivism would have a worse time accommodating realism than other primitivist views. Worries about realism are endemic to primitivist views about color in general. This is in part because of pervasive worries about the causal efficacy of primitive color properties. These concerns will have to be put aside. Relevant work can be found in Gert (2008, pp. 143-145). Much of what he says is about Johnston's core belief Explanation: the colors causally explain our color experiences. Relevant work can also be found in Byrne and Hilbert (2007, pp. 82-85). All three of these philosophers argue that primitive colors can play the causal role required, and what they say can be applied to ostensivism. ${ }^{7}$ For further reading see Allen (2016, Chapter 5).

\subsection{Ostensivism and relationalism}

Is ostensivism compatible with Cohen's relational view $(2004,2009)$ ? It seems not. His view holds that the intrinsic natures of the colors are given by relational descriptions of them. ${ }^{8}$ This said, ostensivism has the potential to be compatible with the colors being relational properties, more generally conceived. To understand why, I must explain an important distinction between the intrinsic nature of a property and an essential property of that property. An example explains this distinction. The property of being a triangle essentially has the property of being more similar to being rectangular than to being pentagonal, but the intrinsic nature of the property of being a triangle is not that it is the property of being more similar to being rectangular than to being pentagonal.

\footnotetext{
6 See Whiteley (1956) for some discussion of ostensive definitions.

7 Byrne and Hilbert (2007) raise different problems for primitivism: the problem of animal color vision and the problem of permuted earth. There is no space to discuss these problems in this paper. See Gert (2008), Brogaard (2009) and Watkins (2010) for relevant discussion in favor of primitivist color realism.

8 I say this because he understands his view to be reductivist (Cohen 2009, p. 10, footnote 16).
} 
The intrinsic nature of the property of being a triangle is that it is the property of being a three-sided figure (picture it).

With this distinction in mind, one can see that ostensivism is compatible with the colors being relational properties. There are positive and impure relational properties (Khamara 1988). The property of being married is an example of the former. This property is biconditionally dependent on the relation 'married to' such that a person $x$ is married iff $x$ is married to someone. The property of being married to Tom is an example of the latter. This property is such that a person $x$ has the property being married to Tom iff there is an individual Tom and $x$ is married to him. A general analysis is as follows:

General relational analysis. A property $\mathrm{P}$ is relational iff there is some relation $\mathrm{R}$ such that it is essential to $\mathrm{P}$ that for all $x$, if $x$ has $\mathrm{P}$, then for some thing(s) $y_{1 \ldots} y_{\mathrm{n}}, \mathrm{R} x y_{1 \ldots} y_{\mathrm{n}}$. (Roberts 2014b, p. 1803)

The ostensivist can hold that the colors fit this analysis. The intrinsic nature of being red is that it is like that (pointing to a red sample), but that property $\mathrm{P}$ has as an essential property being such that it is essential to $\mathrm{P}$ that for all $x$, if $x$ has $\mathrm{P}$, then for some thing(s) $y_{1} \ldots y_{\mathrm{n}}, \mathrm{R} x y_{1} \ldots y_{\mathrm{n}}$. In other words, ostensivism is compatible with the colors being relational properties, for we can understand this not as saying what their intrinsic natures are but as merely giving an essential property of them. For these reasons, ostensivism is compatible with both positive and impure relationalism. Let me quickly address a potential confusion. One may think that all this shows is that ostensive colors can have relational properties not that they can be relational properties. However, to be a relational property, a property just needs to meet the analysis. A property meets the analysis IFF it has as an essential property the property of meeting the analysis. Ostensive colors can have this property, in principle. Thus, ostensive colors can, in principle, be relational properties.

In response, one might argue that the colors do not phenomenally look like relational properties (McGinn 1996, p. 541; Tye 2000, p. 152). If ostensivism is true, the colors must phenomenally look like the properties we are accustomed to in visual color experience. It is unclear, though, whether the cited arguments succeed (Byrne and Hilbert 2001). ${ }^{9}$ Thus, if one as an ostensivist were troubled by color variation cases like Cohen (2004, 2009), it would be worth investigating an ostensivism which holds that the colors of objects depend on relations to subjects. A subjective ostensivism is an open possibility for those who like Cohen's arguments. This is an important difference between ostensivism and standard primitivist views. Cohen's arguments cannot be used to undermine ostensivism.

It is intuitive that nothing can be red and green or teal and scarlet all over at once. If one feels the force of this exclusion principle, one may find Cohen's work unconvincing. ${ }^{10}$ For these people, an objectivist ostensivism is a live option. They need

\footnotetext{
${ }^{9}$ In my opinion, there is a lot of confusion regarding thinking of dispositions as relational properties. I argue in Roberts (2014b) that dispositions are not relational properties, and this is the perspective I take here too.

10 I acknowledge that there is an added complication here that arises due to Cohen's (2009) finegrain/coarse-grain distinction. Coarse-grain colors are supposed to accommodate the exclusion principle
} 
only accept that external objects can have objective phenomenal properties, which many primitivists would probably be willing to do. Of course, those who accept the exclusion principle need not reject all versions of relational ostensivism. For instance, there is room for an objective, relational ostensivism that respects color exclusion. What of a view which holds that the colors depend on the color(s) of the surround and the color(s) of the illuminate and not on minds (Roberts 2017)? Such a view would be a compromise between subjectivism and standard objectivism. I remain neutral about whether we should be relational ostensivists.

\subsection{Ostensivism and Campbell's simple view}

Is ostensivism compatible with Campbell's simple view (1993, 2005)? The answer is that it is inconclusive, because Campbell's view is not precise enough of a formulation of primitivism. He never says what precisely the colors are according to his view, but just provides a series of at least four theses attributing certain properties to the colors. They are as follows:

Distinctness. The colors are not dispositions or physical properties. ${ }^{11}$ (1993, p. 258)

Ground. The colors are the categorical grounds of the dispositions to produce experiences of color. (1993, p. 258)

Transparency. Experience as of color provides knowledge of the categorical color property intervention on which changes the experiences of observers. ${ }^{12}$ (2005, Sect. 2)

Inheritance. The qualitative characters of color experiences are inherited from the qualitative character of the colors. (1993, p. 268)

Ostensivism endorses Distinctness. Ostensivism neither accepts nor denies Ground. Ostensivism but not the simple view, for instance, is compatible with the colors supervening on dispositions to produce experiences of color (McGinn 1996). Campbell's knowledge of the colors relies on a non-propositional knowledge relation distinct from the more familiar propositional knowledge relation. Ostensivism does not rule out Transparency but neither does it require it. There is nothing in its formulation that implies that there is any such thing as a non-propositional knowledge relation. Whether ostensivism is compatible with Inheritance depends on whether the sense of

Footnote 10 continued

to some degree. Other papers have already engaged with this distinction (e.g. see Roberts, 2014a), and so I will not do so here.

11 I take the sense of 'physical' in Distinctness to be narrow (similar to those properties mentioned by physics; see the first line of his paper). I do not understand the narrow sense to exclude the colors being physical more generally. The term 'physical' is often a term of art in philosophy and some sense must be gotten from context. I will not attempt a rigorous definition, as Campbell (1993) gives none.

12 The way I understand Campbell, intervening on the colors changes our experiences, because colors play a causal role in our experiences. This element of Transparency will not be particularly important to this paper. This paper does not focus on the debate surrounding the causal efficacy of primitive colors. 
possession in it, signaled by 'the qualitative character of the colors,' is that of instantiation or that of identity. According to ostensivism, the colors do not have qualitative characters; they are qualitative characters (assuming that Campbell means what I do by 'qualitative character:' how they look). As it is unclear how exactly to interpret Inhereitance, it is inconclusive whether ostensivism is compatible with the simple view. What is clear is that ostensivism is less strict in certain important ways.

\subsection{Ostensivism is not Primitivism}

It should have already occurred to the reader that ostensivism seems rather different from Primitivism. I will now carefully prove beyond a reasonable doubt that it is indeed different. First, ostensivism is nothing like Byrne and Hilbert's primitivism (2007, p. 78) ${ }^{13}$ It is not the view that if a proposition $p$ is about the nature of the colors, then $p$ is expressible only using a purely chromatic sentence. A purely chromatic sentence is one that contains solely topic-neutral and color vocabulary. ${ }^{14}$ By 'topic-neutral' Byrne and Hilbert mean 'general, not pertaining to a specific topic or subject, like physics, psychology, ectoplasmology, ...' (personal correspondence). Examples of purely chromatic sentences are 'Every shade of orange is reddish,' 'Canary yellow is not a shade of blue,' 'Purple is more similar to red than to yellow,' etc. (2007, p. 78). Byrne and Hilbert say in their note 11 that the range of sentences can be extended to include 'red is a warm color' and similar.

Dissimilar to Byrne and Hilbert's primitivism, ostensivism is the view that the colors are phenomenal, non-reducible, structural, categorical properties, and this is a truth about the nature of the colors that is not expressible using a purely chromatic sentence (and certainly expressible without using one, as I just did this). Not even the most basic statement of ostensivism, 'the colors are chromatic phenomenal properties,' is a purely chromatic sentence. It is nothing like the examples. The terms 'phenomenal,' 'non-reducible,' 'structural,' and 'categorical,' as defined, all pertain to philosophy. So, given Byrne and Hilbert's definition, these terms are not topic-neutral and so cannot factor into purely chromatic sentences. ${ }^{15}$ Perhaps, some of the terms are more topic-neutral than others, but Byrne and Hilbert certainly must accept that at least 'nonreducible' is not topic-neutral. If it were topic-neutral, 'reducible' would have to also be accepted as topic-neutral (see their note 11), but then their primitivism would be compatible with the colors being reducible and so with the negation of primitivism. So,

\footnotetext{
13 Byrne and Hilbert do not actually endorse primitivism. In their 2007 paper they are critiquing the view. However, for the sake of brevity, I will refer to the version they propose as 'Byrne and Hilbert's primitivism.'

14 Byrne and Hilbert say, 'Minimal Primitivism [the view that the colors are non-reductive] may be further explicated by the claim that the colors have no non-chromatic nature, in the following sense: if 'It is in the nature of the colors that p' is true, then 'p' is a purely chromatic sentence-a sentence that is (at least) solely composed of topic neutral and color vocabulary' (2007, p. 78). To avoid confusion regarding syntax versus semantics, I modified their definition of non-reductivism slightly in the main text.

15 For some related discussion see Allen (2016, Chapter 7.5). He makes a case that the naïve realist's commitment to Distinctness does not commit him to accepting what I later call 'Propositional Revelation.'
} 
if Byrne and Hilbert's primitivism is true, ostensivism is false. ${ }^{16}$ Byrne and Hilbert's primitivism is some kind of quietism but ostensivism is not.

Second, it should be clear that ostensivism is nothing like Gert's primitivism (2008, p. 130). It is not the view that all fundamental truths about the colors are the kinds of simple things ordinary people know. Ostensivism makes no claims to the effect that the fundamental truths about the colors are all simple things ordinary people know. Ostensivism is the view that the colors are phenomenal, non-reducible, structural, categorical properties, and this is a fundamental truth (if true) about the colors that is not a simple truth ordinary people know but a hard truth most likely do not know. Not even the most basic statement of ostensivism 'the colors are chromatic phenomenal properties' is a simple truth. The use of 'are' in the basic statement has a precise, technical sense in philosophy, and 'phenomenal' is a difficult concept even for philosophers to get their minds around, much less ordinary people.

Simple truths, if the idea is to capture Gert's wanted implication that nothing informative can be said about what the colors are (there are no non-trivial truths about what they are), must strike people without years of training as true and do not require technical concepts to understand. One might retort that if ostensivism is true, the colors are in some sense simple properties. Note that ostensivism does not imply that the colors are simple properties compared to complex (or composed) properties. The view is compatible with binary colors (e.g. orange) being non-reductively composed of unitary colors (red and yellow). Regardless, clearly ostensivism is not the view that there is nothing informative to be said about what the colors are, and this is what is relevant. If ostensivism were not informative (if it were just a trivial truth), the position would not be contentious, but it is. Hence, to learn that ostensivism is correct would be to learn something informative. Thus, we can state definitively that if Gert's view is true, ostensivism is false. Gert's primitivism is clearly a kind of quietism but, as I said, ostensivism is not quietist. ${ }^{17}$

\footnotetext{
16 This cannot be avoided by holding that Byrne and Hilbert mean something special by 'nature.' This is not plausible, given that the following is their exposition of the concept: 'If colors are ways of altering light, for instance, then a description of the nature of canary yellow would certainly need to specify in canonical physical terms the exact way of altering light that is identical to canary yellow. And the fact (if it is one) that canary yellow is more similar to ochre than it is to teal is again something that a description of its nature needs to mention. On the other hand, any defensible description of the nature of canary yellow will omit the fact that some Post-it notes are canary yellow, the fact that canary yellow is Johnston's favorite example of a color, and even the necessary fact that canary yellow is Johnston's actual favorite example of a color' (2007, p. 76).

17 The astute reader may question my categorizing Byrne and Hilbert and Gert's views as kinds of primitivism, given that both views seem to be incompatible with saying that the colors are by their nature or fundamentally non-reducible. One should notice that I defined primitivism thus: 'Primitivism is the view that the colors are non-reductive properties in whatever cogent way or ways shapes are.' Primitivism does not assert that it is in the nature of or fundamental to the colors that they are non-reducible, but it can say, for instance, that shapes and colors are non-reducible in the following sense: nothing much can be said about what they are. Note that I disagree with such a quietist take on shape properties, just as I do for color properties.
} 


\section{Revelation}

This section can most generally be seen as examining the core belief Revelation. Before getting to the meat of this section, I must speak briefly of what I mean by 'core belief.' I define 'core belief' to mean 'intuitive proposition.' What does this mean? It is not important for this article to provide an analysis, but my position is that it means this at minimum: if people had the relevant concepts explained where necessary, they would find a core belief intuitive. This leaves it definitionally open as to whether core beliefs need actually be widely believed, which I think is the right result. Revelation, for example, is not plausibly held by the general population, being too technical. However, this does not mean that it is not intuitive in the relevant sense and so worth considering. Of course, just because a proposition is intuitive does not mean that it is, in fact, true, or that it cannot be rejected. It might be that our intuitions are misguided at times. So, my argument in this paper that ostensivism has an advantage in being able to accommodate my proposed core beliefs is just one piece of a larger puzzle. I will not examine all the pieces of the puzzle in this paper.

\subsection{Propositional revelation and depth}

Revelation is a core belief that goes back to Russell (1912) and Strawson (1989). The idea is often associated with primitivism (McGinn 1996; Chalmers 2006; Byrne and Hilbert 2007: Gert 2008). Johnston (1992, pp. 222-223) famously states Revelation thus: 'The intrinsic nature of [for example] canary yellow is fully revealed by a standard visual experience as of a canary yellow thing.' It is unclear what Revelation thus stated amounts to. A natural reading of 'revealed' is propositional (Byrne and Hilbert 2007). It is like seeing that or appearing that. Hence, a well-known interpretation of Revelation is as follows ${ }^{18}$ :

Propositional revelation (PR). It appears that $p$ after careful reflection on our experiences as of the colors where $p$ is about the nature of the colors iff $p$ is true.

PR is the conjunction of the following two theses:

Infallibility. If it appears that $p$ after careful reflection on our experiences as of the colors where $p$ is about the nature of the colors, then $p$ is true.

Self-Intimation. If a proposition $p$ is about the nature of the colors and $p$ is true, then it appears that $p$ after careful reflection on our experiences as of the colors.

It is somewhat plausible that Infallibility is a core belief, because theories that are unable to accommodate what appears to be true about the nature of the colors after careful reflection (on our experiences as of the colors) are often taken to be false (Hardin 1988; Boghossian and Velleman 1991; Johnston 1992). However, Self-Intimation cannot be a component of a core belief about color, because, ironically, it contradicts a

18 Indeed, this is (basically) Johnston's understanding of Revelation given his clarification on p. 225 as follows: 'The nature of canary yellow is supposed to be fully revealed by visual experience so that once one has seen canary yellow there is no more to know about the way canary yellow is.' 
core belief about color, just not one that has yet been mentioned as such. Roughly, the core belief in question is that the colors are properties about which interesting things can be discovered. It runs as follows:

Depth. The colors are properties the nature of which deep and interesting things can be discovered via philosophical and scientific investigation.

If Self-Intimation were true, all truths about the nature of the colors would be revealed to be true upon careful reflection on experience. So, nothing deep and interesting about the nature of the colors would be left to be discovered via philosophical and scientific investigation. Thus, PR cannot be a core belief about color if Depth is. Depth is a core belief. So, PR is not.

Why should we believe that Depth is a core belief? The binary/unitary distinction, although orthodoxy today, was once (and still is to a degree, Mizrahi 2009; Jameson 2010) the subject of philosophical and scientific scrutiny (Allen 2011, 2016, Chapter 7.4). Given that this investigation into the nature of the colors took place, those who took part probably thought that the colors were properties about which, intuitively, such an investigation could be fruitful. Further, the fact that philosophers have for centuries been trying to determine what the colors are (that the ontology of color exists as an area of enquiry) suggests that they found it intuitive that the colors were the kinds of properties suitable for such an enquiry. In sum, the decades old investigation into the nature of the colors by both philosophers and scientists suggests that Depth is a core belief, for were it not, the investigation would probably not have occurred. Although more discussion of Depth is called for, I leave the debate here for the present paper. The proposition is intuitive enough to plausibly be called a 'core belief,' and the vast majority of philosophers will probably accept that it is true regardless. Besides, given my understanding of 'core belief,' I think whether Depth is a core belief is ultimately an empirical question and so is best addressed by an empirical paper.

Gert (2008, p. 142) proposes an alternative account of Revelation he calls 'Modest Revelation,' which is supposed to be a weaker version. It runs as follows:

Modest revelation (MR). A complete understanding of what canary yellow is can be given by an experience as of something canary yellow, in someone with normal human vision who has already acquired color concepts.

MR seems to imply modest self-intimation (or something close enough to be similarly problematic): if a proposition $p$ is about the nature of the colors and $p$ is true, then it appears that $p$ to someone with normal human vision who has already acquired color concepts. If so, MR like PR is incompatible with Depth (or something similar enough to be worrying). ${ }^{19}$ Given the nature of Gert's primitivism this is not particularly surprising. Anyway, at best, MR is not abundantly clear and under a natural interpre-

\footnotetext{
19 Kalderon (2007, p. 587) proposes what he calls 'Manifestation' (M). The view seems to be as follows: the qualitative nature of the colors (which have to do with the structure of color space, e.g. claims involving Unity and the similarity, difference, and exclusions relations) are revealed in experiences of normal observers. M would be incompatible with Depth if we thought Depth extended to the Unity relations (Allen 2016, Chapter 7). If there are colors we cannot see, it would. Anyway, $\mathrm{M}$ is too weak to be a version of Revelation proper.
} 
tation implies modest self-intimation. This is reason enough to find MR wanting and to struggle to do better.

\subsection{Phenomenal revelation}

In this paper, I advance the idea that Revelation should be understood phenomenally. The idea is that when we have an experience as of canary yellow it is not that it appears that the intrinsic nature of canary yellow is whatever it is but that its intrinsic nature is phenomenally presented. ${ }^{20}$ This should not be understood to be propositional in the same way as 'appearing that' is normally understood in that it should not be understood to be cognitive and involve thought, and preferably it should not be understood as propositional at all (Crane 2009). To be clear, the idea is not that it appears that the intrinsic nature of canary yellow is whatever it is in the way that it appears that the answer to $2+2=4$. The idea is that when we have experiences as of canary yellow, the very entity that is the intrinsic nature of canary yellow is phenomenally presented, and that this can be the case without any propositions appearing true before or after careful reflection. Revelation so interpreted runs as follows:

Phenomenal revelation (PHR). The phenomenal properties that define the phenomenal characters of experiences as of objects having colors are the intrinsic natures of the colors. (In other words, the phenomenal colors or the colors as we see them in perception are the intrinsic natures of the colors.)

PHR is close to the surface in Johnston's Revelation and captures an important element of naïve realism: that our color experience puts us into direct contact with color properties as they really are, intrinsically. Hence, it has a strong claim to being a core belief. When we have an experience as of an object being canary yellow, that phenomenal quality presented, given as covering the object, is the very entity that is the intrinsic nature of canary yellow. According to PHR, then, there is no entity that is identical with what canary yellow really is (its intrinsic nature) with which our experience merely indirectly presents us as if it were an indicator of a reality hidden behind a phenomenal veil. Rather, because PHR holds that the phenomenal properties that define our phenomenal characters are the intrinsic natures of the colors, PHR lifts the phenomenal veil and allows for the seeing of colors as they really are. Also, importantly, PHR is compatible with Depth. PHR does not require that anything which is true of the colors appear true in cognition or thought or in any way whatsoever. So, PHR is very plausibly a core belief. It is close to the surface in Johnston's statement, captures an important element of naïve realism, and is compatible with Depth.

\footnotetext{
20 I caution the reader from reading 'phenomenally presented' so as to imply being presented in any sense used for ordinary objects. I phenomenally experience the circular object as being square. So, squareness is phenomenally presented, but nowhere around. How precisely to understand phenomenal experience is a topic best left for a paper on perception (see, for example, Byrne and Logue 2008). Suffice to say, I would prefer to hold that phenomenal presentation is a fundamental perceptual notion that is involved in both good and bad cases of perception. Disjunctivism about phenomenal character may raise some issues with ostensivism being compatible with irrealism. If there are no colors, and one is a (relevant kind of) disjunctivist about phenomenal character, we have no phenomenal color experiences.
} 
PHR strikes me as highly intuitive. I suspect it is the truth behind why the various statements of Revelation have sounded plausible. Given my understanding of 'core belief,' I think that, just as with Depth, whether PHR is a core belief is ultimately an empirical question. Perhaps an experimental philosophy program could test whether people agree with PHR over its competitors. Because of the complexity of these propositions, it may be hard to get non-philosophers to understand the differences. Perhaps what could be done, though, would be to explain to participants what the relevant terms mean, give them time to think, and then see which Revelation they prefer. Alternatively, perhaps simpler statements can be used which still mostly capture the ideas in question. If participants prefer PHR this would be a reason to suspect that it is a better candidate for a core belief than its competitors. Of course, intuitions can misfire. I am not saying that any such study would show PHR to be unassailable; it would just go a long way to demonstrating the proposition's intuitiveness.

\subsection{Phenomenal revelation versus transparency}

PHR has an affinity with knowledge by acquaintance views of Revelation like Campbell's Transparency (T) (see Sect. 2.5 above). PHR is different from T in two salient and important ways. First, PHR unlike T does not require any non-propositional knowledge relation. It at most requires a non-epistemic acquaintance relation (the converse of presentation). ${ }^{21}$ Second, PHR unlike T speaks of the intrinsic natures of the colors. Specifically, PHR is logically incompatible with the colors being, for example, lowlevel physical properties, while $\mathrm{T}$ is not (this is uncontroversial: Campbell thinks $\mathrm{T}$ is problematic for such views but not that it is logically incompatible with them 2005 , Sect. 2). So, T unlike PHR does not require that the colors are, intrinsically, as we see them to be.

If we had to choose between PHR and T as being the correct way of capturing Revelation, the differences between them would give us reason to prefer PHR. First, PHR does not require a non-epistemic knowledge relation. Some find such a relation mysterious (Fumerton 2014). Belief is propositional and thought required for knowledge, so how can there be non-propositional knowledge? Second, presumably animals without the cognitive sophistication to know of things (e.g. a fish of sorts or a spider or a bug perhaps) could still see colors the way we do as long as they had (stable?) experiences with the same phenomenal characters, but $\mathrm{T}$ would not be true for such animals. Hence, T presumably cannot capture the idea attributed to Strawson (1989) that Revelation is necessarily true of color experience (Johnson 1992, p. 224). PHR though can. In this way, PHR is more fundamental than T and so, in this way, superior. Third, that PHR requires that we see color properties as they really are, intrinsically, is also an advantage, because this allows PHR to capture an important element of naïve realism. Regardless, there is no need to choose between PHR and T. Revelation is an amorphous notion. Therefore, both ideas can be present to some degree in it, and as I

\footnotetext{
21 Fumerton (2014) provides a good discussion of the issues with understanding an epistemic acquaintance relation. He speculates that the idea may be due to Russell equivocating between the relation of acquaintance and a special kind of knowledge of truth whose sole source is acquaintance.
} 
said in Sect. 2.5, ostensivism is compatible with T. Thus, all I need is for PHR to be a core belief about color. PHR and T do not have to be enemies.

\section{The advantages of ostensivism}

So far, I have defined ostensivism and differentiated it from other views and have discussed Revelation in detail and made a case for Depth and Phenomenal Revelation (PHR). Now, in this final major section, I will show that only ostensivism can accommodate both Depth and PHR. I compare ostensivism to non-ostensivist views: reductive views and Primitivism. As most of what is required to complete this section has been previously set up, what follows should be easy to understand, and so I will not spend much time making my argument.

\subsection{Compatibility with phenomenal revelation}

PHR is that the phenomenal properties that define the phenomenal characters of experiences as of objects having colors are the intrinsic natures of the colors. The ostensivist answers the metaphysical question, 'what are the colors?' by saying that the intrinsic natures of the colors are those phenomenal properties that define the phenomenal characters of experiences as of objects having colors. Thus, clearly, ostensivism is true iff PHR is true, and so ostensivism can clearly accommodate PHR and, in fact, even do so necessarily. The fact that ostensivism and PHR have a bi-conditional logical relationship is not a strange result. In fact, it is exactly what a primitivist might have expected, as Revelation and primitivism are thought to be closely related (Strawson 1989; Johnston 1992; Byrne and Hilbert 2007). Thus, I see ostensivism's connection with PHR, which is by design, to be as it should be.

Reflectance dispositionalism, micro-structuralism, appearance dispositionalism, and Cohen's view must all deny that the phenomenal properties that define the phenomenal characters of experiences as of objects having colors are the intrinsic natures of the colors. All of these views are non-ostensivist. They hold that the intrinsic natures of the colors are not given by their phenomenal characterizations but by something else. ${ }^{22}$ For example, reflectance dispositionalism says that the intrinsic nature of redness is given by the description, 'redness is the disposition to reflect a particular proportion of incident light at each wavelength of the visible spectrum.' Thus, with respect to PHR, ostensivism can accommodate this core belief, whereas the relevant non-ostensivist views cannot.

Can Primitivism accommodate PHR? Byrne and Hilbert's precise version of primitivism is that if a proposition $p$ is about the nature of the colors, then $p$ is expressible only using a purely chromatic sentence. So, this version cannot accommodate PHR. This core belief implies ostensivism, and this view on the nature of color, as I have

\footnotetext{
22 Johnston (1992) says that appearance dispositionalism is compatible with a grain of truth in Revelation. I do not take issue with this. However, this grain of truth is insufficient to accommodate Phenomenal Revelation. Phenomenal Revelation implies ostensivism, an entirely different view from appearance dispositionalism.
} 
already discussed, is clearly not expressible (only) using a purely chromatic sentence. Gert's precise version of primitivism is the view that all fundamental truths about the colors are simple truths ordinary people know. So, Gert's primitivism cannot accommodate PHR either. PHR implies that ostensivism is true, a fundamental truth about the colors that, as I have argued, is not a simple truth ordinary people know but a hard truth most likely do not know. Thus, we can conclude that, although ostensivism clearly accommodates PHR, Primitivism cannot.

\subsection{Compatibility with depth}

We come finally to considering Depth: The colors are properties the nature of which deep and interesting things can be discovered via philosophical and scientific investigation. All non-primitivist views can clearly accommodate this core belief. For example, reflectance dispositionalism tells us (if true) something interesting about the nature of the colors via philosophical and scientific investigation. The same goes for the other non-primitivist views like micro-structuralism and even Cohen's relational view. Ostensivism can also clearly accommodate Depth. Ostensivism tells us that the colors are phenomenal properties, which are non-reducible, structural, and categorical like shapes, and surely this would be an interesting discovery about the nature of the colors via philosophical investigation, an investigation that, as should be clear, is not oblivious to the findings of science.

Unlike ostensivism, Primitivism cannot accommodate Depth. Byrne and Hilbert's primitivism is in trouble when it comes to Depth, for it implies that there are no truths about the nature of the colors but those only expressible using purely chromatic sentences. So, Byrne and Hilbert's primitivism is at most compatible with a much-weakened version of Depth that is written to exclude truths expressible in nonchromatic sentences. Gert's primitivism also has a serious problem. His view is that all fundamental truths about the colors are simple truths ordinary people know. So, according to his view, there can be no fundamental truths about the nature of the colors to be discovered via philosophical and scientific investigation. So, Gert's primitivism is at most compatible with a much-weakened version of Depth written to exclude fundamental truths (e.g. truths about what the colors are). ${ }^{23}$ In sum, ostensivism can accept Depth, Primitivism at best only a much-weakened version.

\section{Conclusion}

My goal for this paper has been modest: to propose a precise variant of primitivism, 'ostensivism,' and show why it has an advantage over other views on color, specifically, that only it can accommodate both Phenomenal Revelation and Depth. Ultimately, whether this is an advantage depends on whether Phenomenal Revelation and Depth are really core beliefs. If one does not believe whatsoever that Revelation is a core belief, one will not be convinced by the reasons I gave for accepting Phenomenal

23 Gert could include some (but not all) truths about the nature of the colors by setting a certain level of fundamentality for what counts as 'fundamental' in my statement of his view. 
Revelation. Similarly, those who hold firmly to a view like Byrne and Hilbert's or Gert's will likely not find what I say in favor of Depth convincing and so neither Phenomenal Revelation. I ask only that out of humility such staunch opposition consider this paper as showing why ostensivism might have an advantage over other views in being able to accommodate both the propositions in question.

Acknowledgements I originally started to play with the ideas that evolved into this paper back in the autumn of 2013 while still in graduate school. I am to this day thankful to my advisor, Philip Percival, for his rigorous exactitude. It took almost five additional years to clearly formulate my thoughts and get them published. I would not have been able to do this at all without the philosophical training I received from Philip. Keith Allen read an earlier version at least twice. His comments and suggestions led to me formulating the core belief I call 'Depth.' I am also appreciative to Joshua Gert and Alex Byrne for their email discussions. Finally, I am thankful to my loving wife with whom I discuss my ideas often.

Open Access This article is distributed under the terms of the Creative Commons Attribution 4.0 International License (http://creativecommons.org/licenses/by/4.0/), which permits unrestricted use, distribution, and reproduction in any medium, provided you give appropriate credit to the original author(s) and the source, provide a link to the Creative Commons license, and indicate if changes were made.

\section{References}

Allen, K. (2009). Inter-species variation in colour perception. Philosophical Studies, 142, 197-220.

Allen, K. (2011). Revelation and the nature of color. Dialectica, 65, 153-176.

Allen, K. (2016). A naive realist theory of color. Oxford: Oxford University Press.

Armstrong, D. (1968). A materialist theory of the mind. London: Routledge \& Kegan Paul.

Boghossian, P. A., \& Velleman, J. D. (1991). Physicalist theories of color. Philosophical Review, 100, 67-106.

Brogaard, B. (2009). Perspectival truth and color primitivism. In C. Wright \& N. Pedersen (Eds.), New waves in truth (pp. 249-266). New York: Palgrave Macmillan.

Byrne, A., \& Hilbert, D. (2001). Do colors look like dispositions? Reply to Langsam and others. The Philosophical Quarterly, 51, 238-245.

Byrne, A., \& Hilbert, D. (2003). Color realism and color science. Behavioral and Brain Sciences, 26, 3-21.

Byrne, A., \& Hilbert, D. (2004). Hardin, Tye and color physicalism. Journal of Philosophy, 101, 37-43.

Byrne, A., \& Hilbert, D. (2007). Color primitivism. Erkenntnis, 66, 73-105.

Byrne, A., \& Logue, H. (2008). Either/or. In Adrian Haddock \& Fiona Macpherson (Eds.), Disjunctivism: Perception, action, knowledge (pp. 58-94). Oxford: Oxford University Press.

Campbell, J. (1993). A simple view of color. In J. Haldane \& C. Wright (Eds.), Reality, representation and projection (pp. 257-268). Oxford: Oxford University Press.

Campbell, J. (2005). Transparency versus revelation in color perception. Philosophical Topics, 33, $105-115$.

Chalmers, D. J. (2006). Perception and the fall from Eden. In T. S. Gendler \& J. Hawthorne (Eds.), Perceptual experience (pp. 49-125). Oxford: Oxford University Press.

Cohen, J. (2004). Color properties and color ascriptions: A relationalist manifesto. Philosophical Review, $113,451-506$.

Cohen, J. (2009). The red and the real. Oxford: Oxford University Press.

Crane, T. (2009). Is perception a propositional attitude? Philosophical Quarterly, 59, 452-469.

Fumerton, R. (2014). Knowledge by acquaintance vs. description. In E. N. Zalta (Ed.), The Stanford Encyclopedia of Philosophy. https://plato.stanford.edu/archives/win2012/entries/color/.

Gert, J. (2008). What colors could not be: An argument for color primitivism. The Journal of Philosophy, $105,128-155$.

Hardin, C. L. (1988). Color for philosophers. Cambridge: Hackett.

Jackson, F. (1977). Perception: A representative theory. Cambridge: Cambridge University Press.

Jackson, F. (1982). Epiphenomenal qualia. Philosophical Quarterly, 32, 127-136.

Jameson, K. (2010). Where in the World Color Survey is the support for color categorization based on the Hering Primaries? In J. Cohen \& M. Matthen (Eds.), Color ontology and color science (pp. 179-202). Cambridge: MIT Press. 
Johnston, M. (1992). How to speak of the colors. Philosophical Studies, 68, 221-263.

Kalderon, M. E. (2007). Color pluralism. The Philosophical Review, 116, 563-601.

Khamara, E. J. (1988). Indiscernibles and the absolute theory of space and time. Studia Leibnitiana, 20, $140-159$.

Levin, J. (2000). Dispositional theories of color and the claims of common sense. Philosophical Studies, $100,151-174$.

Maund, B. (2012). Color. In E. N. Zalta (Ed.), The Stanford Encyclopedia of Philosophy. https://plato.stan ford.edu/archives/win2012/entries/color/.

McGinn, C. (1983). The subjective view: Secondary qualities and indexical thoughts. Oxford: Oxford University Press.

McGinn, C. (1996). Another look at color. The Journal of Philosophy, 93, 537-553.

Mizrahi, V. (2009). Is colour composition phenomenal? In D. Skusevich \& P. Matikas (Eds.), Color perception: Physiology, processes and analysis (pp. 185-202). New York: Nova Science Publishers.

Papineau, D. (2011). Phenomenal concepts and the private language argument. American Philosophical Quarterly, 48, 175-184.

Putnam, H. (1975). The meaning of meaning. Philosophical papers, Vol. II: Mind, language, and reality. Cambridge: Cambridge University Press.

Roberts, P. (2014a). Color relationalism, ordinary illusion, and color incompatibility. Philosophia, 9, 1085-1097.

Roberts, P. (2014b). Parsing the rainbow. Synthese, 191, 1793-1811.

Roberts, P. (2017). An ecumenical response to color contrast cases. Synthese, 194, 1725-1742.

Russell, B. (1912). The problems of philosophy. Oxford: Oxford University Press.

Schaffer, J. (2005). Quiddistic knowledge. Philosophical Studies, 123, 1-32.

Smart, J. J. C. (1963). Philosophy and scientific realism. London: Routledge \& Kegan Paul.

Strawson, G. (1989). Red and 'Red'. Synthese, 78, 193-232.

Thompson, E. (1995). Colour Vision: A study in cognitive science and philosophy of perception. New York: Routledge.

Tye, M. (2000). Consciousness, color, and content. Cambridge: MIT Press.

Watkins, M. (2010). A posteriori primitivism. Philosophical Studies, 150, 123-137.

Whiteley, C. H. (1956). Meaning and ostensive definition. Mind, 65, 332-335.

Wittgenstein, L. (1953). Philosophical investigations. Oxford: Basil Blackwell.

Yablo, S. (1995). Singling out properties. Philosophical Perspectives, 9, 477-502. 